\title{
Analysis of Emotional Intelligence for the Intellectual Capital Growth
}

\author{
Nadezhda N. Pokrovskaia \\ ${ }^{1}$ Department of Public Relations and Advertising \\ Herzen State Pedagogical University of Russia; \\ ${ }^{2}$ Department of Advertising and Public Relations \\ Peter the Great Saint-Petersburg Polytechnic University \\ St. Petersburg, Russia \\ 1nnp@herzen.spb.ru, 2nnp@spbstu.ru
}

\author{
Svetlana O. Snisarenko ${ }^{1}$, Janna S. Safronova ${ }^{2}$ \\ Department of Human resources management \\ St. Petersburg University of Management Technologies and \\ Economics \\ St. Petersburg, Russia \\ ${ }^{1}$ sos60@inbox.ru, ${ }^{2}$ shan_safronova@mail.ru
}

\author{
Dmitry S. Brazevich \\ Department of Social and Human sciences \\ St. Petersburg National Research University of Information Technologies, Mechanics and Optics \\ St. Petersburg, Russia \\ brazevich1986@mail.ru
}

\begin{abstract}
The study of factors of organizational intellectual capital development is based on the analysis of both rational and emotional components of internal organizational processes and external communications with partners and customers. The analysis of emotional intelligence shows a number of positive effects that should be used in planning business processes. Sociopsychological methods of interrogation and tests give unstable results, the emotional intelligence assessment needs repetition to obtain significant and valuable conclusions or requires additional methods such as interviews, as implemented in the presented study. The article shows the correlation between the type of employment and the emotional intelligence of employees. Recommendations are given on the use of the analysis of emotional intelligence for the development of organizational processes in a company and the improvement of the organization's intellectual capital management system based on the inclusion of both cognitive-rational elements of knowledge, including formalized data and practices, in the analysis of intellectual capital, and affective and emotional elements that determine organizational components of intellectual capital and improvement of business-processes.
\end{abstract}

Keywords - intellectual capital; ethics; emotional intellect; precarization; types of employment

\section{INTRODUCTION}

Assessment and development of the intellectual capital of a company is based on an analysis of institutional and innovative components [1] and often is limited with this structure. The institutional capital of the organization assumes the existence of existing relations, corporate social capital [2] and a culture that determines the nature and effectiveness of internal and external communications [3]. Innovative capital is considered as the ability and willingness of a company to change in response to the requirements of the market and society, the

The research was carried out with the financial support of the Russian Foundation for Basic Research, research project No. 16-29-12965 / 18. requests of internal and external clients and partners [4], and various stakeholders.

The analysis of emotional intelligence as an integral part of the organization's intellectual capital is based on the methodological possibility of a) formalizing questions on the ability to manage affective processes and the respondent's awareness of his emotional behavior, b) quantitative assessment, c) recognition and management based on the data obtained. The data obtained by the researchers $[4,5,6]$ about the relationship between the level of emotional intelligence and the ability to manipulate the interlocutor and the negative correlation between the coefficient of emotional intelligence and the level of ability to recognize lies, allow us to approach the development of differentiated tools for analyzing emotional intelligence for the purpose of assessing the intellectual capital of an organization and developing proposals for using modern analysis tools in order to improve knowledge management in the organization, taking into account the various forms, in particular, the choice by employees of "constancy" of work, i.e. full-time or part-time, freelance and other forms of precarious work. This article describes the implementation of the emotional intelligence scores to understand the differences between full-time office workers and agents as their ability to create the additional value for the company.

\section{EMOTIONAL INTELLIGENCE AS A SUBJECT OF ECONOMIC AND MANAGERIAL RESEARCH}

The affective elements of communication and decision making are a complex resultant of signals that is formed by an organism for the quick development of a significant volume of data from the external environment. For mastering by machine tools, today the content of emotions is encoded and decrypted by a person and is set to the artificial intelligence by the expert training. At the same time, emotions are complicated for the human rational comprehension due to the huge amount and 
complexity of information to be logically built into a chain of deliberation that allows machine leaning tools to digitalize them and to use emotions as the subject for data mining.

\section{A. Affective components of intelligence}

The rationalization of modernized society and the postmodernization response to the modernity' over-rationalization determined the shift of interest in up-to-date research from the cognitive aspects of knowledge management in their quantitative form to the study of knowledge in the whole cognitive, affective and behavioral aspects with the integrity of qualitative and quantitative methods. Modernity as a society type with its differentiated, rational and structured approach, according to E. Giddens [7, 8], allowed humans to transfer some of the most time-consuming routine tasks to computers. Exemption from routine operations revealed that "we too often tackle the dilemmas of the $20^{\text {th }}$ century, having at our disposal an emotional repertoire adapted to the needs of the Pleistocene" [9]. Studies of the organization of neural-psychic activity of various biological species and of the human brain made it possible to find out the basic mechanisms of information processing and decision-making by the human conscience. Nevertheless, neural networks, imitating the work of the brain, do not bring us closer to understanding how emotions work as an independent phenomenon in decision-making and acting by a living organism, since computers were built as homogeneous computing capacities, and neural networks were created as a set of perceptrons that can be linked to any network by the will of the developer. While the amygdala in the mammalian brain is an independent part of the brain that specializes in the formation of emotions and social relations and on quick sorting of information as a danger detector that regulates the body's readiness for instant reaction; in a similar way, emotions and affective components in modern organizations form the basis of communication efficiency, internal (empathy and mutual understanding within the work team for collective action), and external (the ability to understand the clients, perceive and relay their needs and expectations).

Studies revealed [10] that employees with higher indicators of emotional intelligence demonstrate a smoother and faster movement up the career ladder and higher sales, but a lower ability for independent activity and for recognition of false information in interpersonal communication. In the surgical separation of the amygdala from the mammalian main brain, a living organism loses the desire to compare itself with others, build competitive relations or cooperative links, and is not able to perceive its own and other people's position in the hierarchy of a group or community [11].

It can be concluded that intelligent systems for searching, processing and analyzing information rely on the unity of the space of logical reasoning, while emotional intelligence treats and processes signals that indicate danger, and helps to ensure safety and survival based on the reaction of the organism itself and on the basis of group actions. The organization as a collective actor has to measure the emotional intelligence to improve its functioning.

\section{B. Emotional Intelligence Analysis and Corporate Intellectual} Capital

From the point of view of business process management, analysis of the emotional sphere allows managers to provide:

- personnel management and career planning, taking into account the interaction between people in the company;

- prevention or reduction of risks associated with the human factor;

- improving the external communication of the business with participants in the value chain, primarily partners and customers the direct negotiations and interpersonal communication take place with, which plays a decisive role for them to decide on collaborative strategy and cooperation with the company, identification with the corporate value proposal through the acquisition and use of its product, and etc.;

- better distribution of human resources according to the structure of organizational business processes and the value chain: people with higher emotional intelligence are more effective in group interactions, people with less developed emotional sphere are able to show better results in offline work outside the team and in analytical tasks.

The assessment of intellectual capital in corporate management and entrepreneurial activity includes not only the assessment of patents, trademarks, and customer reputation, but also relies heavily on the assessment of the overall business reputation of the company and its ability to evolve in accordance with feedback from the external environment.

If the analysis of "weak signals" from the external environment has long been the subject of intellectualization by the economic and business analysis systems (business intelligence), the analysis of emotional intelligence so far takes its place only in rare studies of corporate relations, which seems insufficient way to use this notion and the measurement tools that can produce additional help for the growth of the intellectual capital of a company.

\section{Correlation of components of emotional intelligence and type of employment}

Socio-psychological research based on tests shows the relationship of emotional intelligence and the choice of a permanent or precarious type of employment. Thus, in a study conducted with the participation of the authors [12], a positive correlation was found between the level of emotional intelligence and the productivity of employees of a real estate agency. The interesting differences were revealed due to the analysis of the features reflecting the employee's choice between the degrees of "sustainability" of their employment.

This measure of sustainability is reflected in the choice between the roles of a full-time office employee and an agent. The agency as a specific activity can be considered as an extremely unstable, precarious form of employment, since the agent is not socially protected, does not receive payments due to vacation or illness, is not integrated into an organizational system for formal or informal support or help in the case of any 
problems outside of direct professional interaction with the agency. So, opposite signs of correlation were found in understanding one's feelings and emotions (element No. 1 of emotional intelligence) and noticeable differences in the awareness of the emotions of others (element No. 3) (respectively, lines 1 and 3 in Table 1):

TABLE I. CORRELATION BETWEEN EMOTIONAL INTELLIGENCE AND PRODUCTIVITY LEVEL BY EMPLOYEES' CATEGORIES (PEARSON CORRELATION)

\begin{tabular}{|l|c|c|}
\hline \multirow{2}{*}{ Emotional intelligence components } & \multicolumn{2}{|c|}{ Productivity by categories } \\
\cline { 2 - 3 } & $\begin{array}{c}\text { Office staff } \\
\text { members }\end{array}$ & Agents \\
\hline $\begin{array}{l}\text { Understanding of oneself, awareness } \\
\text { of one's emotions }\end{array}$ & 0,269 & $-0,152$ \\
\hline Self-control & 0,072 & 0,014 \\
\hline Awareness of the emotions of others & $\mathbf{0 , 5 6 2}$ & $\mathbf{0 , 3 8 9}$ \\
\hline Relationship building & 0,083 & 0,121 \\
\hline Emotional Intelligence & 0,235 & 0,128 \\
\hline
\end{tabular}

The only significant correlation revealed in the study reflects an indicator of awareness of other people's emotions, while this indicator is significantly higher (0.562) for full-time office employees who are integrated in the systemic regular communications within the organization and in interactions with various types of clients in the office than agents (0.389).

The free interviews that followed the tests, permitted to fid out that full-time office workers note the specific ability of agents to manipulate, which, it would seem, contradicts the data on a lower level of emotional intelligence. However, these assumptions indirectly confirm the data obtained in a number of studies [13, 14], which revealed an inverse correlation between the manipulative properties of a person and a measurement of emotional intelligence and, at the same time, an inverse correlation with the competence of recognizing lies and false behavioral patterns.

Based on the data obtained, it is possible to preliminary formulate the hypothesis that full-time employees have a higher ability for empathic interaction with clients and partners, but a slightly lower ability to build efficient productive relationships than employees engaged in precarious forms of labor relations. Although the correlation indices obtained in this study are low, the different signs of the obtained correlation values and differences in the levels of correlation are to be verified further, to test the hypothesis.

\section{ANALYSIS OF EMOTIONAL INTELLIGENCE AS A FACTOR IN CHOOSING THE DEGREE OF PRECARIZATION OF EMPLOYMENT}

The high correlation between the emotional intelligence and productivity of employees is important for the management of human resources, it is necessary to point our the significance of this conclusion for the development of intellectual capital management of a particular organization. This results relates to the different approaches to be implemented to attract employees with different types of emotional intelligence to different forms of labor relations. The adaptation of the structure of employment to the different kinds of the emotional intelligence of the people involved can be highlighted as a specific subject for the research and management of the growth of a company intellectual capital.

\section{A. Rational and Emotional Intelligence as a Subject of Behavioral Research}

Behavioral research is seen as a tool for quantifying the qualitative phenomena of cognition, thinking, and decision making. So, the role of "social intelligence" is to determine the body's ability to predict in interpersonal interaction, the competence of "acting reasonably in human relations" [15, 227], and, from a behavioral perspective, this factor can be measured. It is also interesting for companies to comprehend the results of evaluating emotional intelligence from the perspective of transactional analysis in order to creativize labor as the basis of the value chain in the knowledge economy, to develop the gamification approaches and to expand the use of the creative abilities of the humans involved.

If creativity often relies on the development of divergent thinking, but the building effective organizational relations requires convergent thinking, it is advisable to combine human resources engaged in stable labor contracts with high social integration and security (convergent thinking) and precarious, "unstable" forms of contracts, design work, orders (divergent thinking). The analysis and measurement of the emotional intelligence can be used as a tool to improve this combination.

\section{B. Emotional intelligence as a formalized component of the company's intellectual capital}

The intellectualization of everyday life, including the assessment of emotional intelligence for business purposes, provokes the specific ethical issues based on a humanistic search for identity and personal development, in particular, for the transition from manipulative techniques of interaction to genuine being and interpersonal contact. In this regard, the question arises of the possibility and admissibility of applying the assessment of emotional intelligence to the development of the intellectual capital of a company.

In particular, three groups of questions arise:

- financial and economic issues of accounting, ie accurate assessment of the relationship between indicators of emotional intelligence and the company's ability to increase its market value based on the development of communications due to the correct distribution of workers with different indicators of emotional intelligence on different functions;

- technological tasks are associated with pattern recognition, emotions and reactions and machine learning, which can be used for automatic online monitoring of the behavioral characteristics of specific employees in order to subsequently offer them various forms of employment;

- ethical problems are associated with the need to take into account the will of the employees themselves - for example, if a particular individual would like to develop certain qualities, for example, the ability to integrate into the team, how appropriate it will be to offer him precarious work in which he is more effective due to his personal characteristics, thereby questioning his right to personal choice. 
The issues mentioned are both narrowly economic and managerial in character, and ethical and regulatory in nature [15]. If the technological capabilities of continuous monitoring are already implemented, which puts a person in a situation of lack of choice (the modern world is almost completely riddled with digital counterparts, video surveillance and face recognition systems, etc.), then the regulatory aspects so far remain only subject of discussion.

Finally, the analysis of emotional intelligence, of course, can be useful not only for training within organizational structures, but also for improving the educational system, the learning processes organization at high schools as well as at universities.

\section{CONCLUSION}

Intellectual capital at the macro level of the region and the state and at the micro level of the company is based on both rational and emotional-communicative elements, which determines the humanization of the economy. Digitalization already allows you to train "smart" devices and "smart" environments to respond to human gestures and facial expressions, neurocommunications will directly transmit feelings and emotions [16] to interlocutors. But issues of using data, for example, control over the assessment of the level of emotional intelligence of a particular employee of a company [17], should be decided taking into account the rights to the citizen's private life, free will and choice, and the preservation of personal information.

It is assumed that data on emotional intelligence will be used to expand opportunities and deepen the degree of selfrealization and effectiveness of a person, but it is also necessary to consider the socio-economic, managerial, political and cultural consequences of studying emotional intelligence as a component of the intellectual capital of the individual, not just the region or company.

\section{REFERENCES}

[1] M.E. Van Buren, "A Yardstick for Knowledge Management. American Society for Training and Development, Inc.", in Training and Development, 1999, Vol. 53, No 5, pp. 71-78.

[2] N.N. Pokrovskaia, M.Yu. Ababkova, V.L. Leontieva, and D.A. Fedorov. "Semantics In E-Communication For Managing Innovation Resistance Within The Agile Approach," in The European Proc. of Social \& Behavioural Sciences EpSBS, 2018, Vol. LI, pp.1832-1842.
[3] N.N. Pokrovskaia, I.R. Trostinskaia, and A.S. Safonova, "Professionalization of education within the digital ecnomy and communicative competencies," IEEE VI Forum Strategic Partnership of Universities and Enterprises of Hi-Tech Branches (Science. Education. Innovations) (SPUE) 2017. N.Y.: IEEE Explore, 2017, pp. 29-32

[4] G. Roos and J. Roos, "Measuring Your Company's Intellectual Performance," in Int. Journal of Strategic Management, 1997, Vol. 30, N 3, pp. 413-426.

[5] H. Livingstone, M. Nadjiwon-Foster, and S. Smithers Emotional Intelligence and Military Leadership. Report Prepared for the Canadian Forces Leadership Institute. Ottawa: DND, 2002.

[6] D. McClelland, "Identifying Competencies with Behavioral-Event Interviews," Psychological Science, 1998, Vol. 9, No 5, pp. 331-339.

[7] J. Barling, F. Slater, and E.K. Kelloway, "Transformational leadership and emotional intelligence: An exploratory study," in The Leadership and Organizational Development Journal, 2000, Vol. 21, No 3, pp. 157161.

[8] A. Giddens, The Consequences of Modernity. Cambridge: Polity Press, 1990.

[9] A. Giddens, Modernity and Self-Identity. Self and Society in the Late Modern Age. Cambridge: Polity Press, 1991.

[10] D. Goleman, Emotional Intelligence: Why It Can Matter More Than IQ. N.Y.: Bantam Books, 1995.

[11] S.J. Stein and H. Book, The EQ edge: Emotional intelligence and your success. Hoboken, N.J.: John Wiley \& Sons, 2010.

[12] N.N. Pokrovskaia, D.V. Golohvastov, and S.O. Snisarenko, "Institutional Confidence and Economic Intelligence for the Performance at Macro and Micro Networks," in Proc. of the 4th International Conference on Management, Leadership and Governance ICMLG 2016 Host. Reading, UK: Academic Conferences and Publishing International Limited, 2016. pp. 255-263.

[13] E.J. Austin, D. Farrelly, C. Black, and H Moore, "Emotional intelligence, Machiavellianism and emotional manipulation: Does EI have a dark side?", in Personality and Individual Differences, 2007, No 43, pp. 179-189.

[14] D. Dabke, "Role of parental emotional intelligence and perceived parental leadership behaviour on satisfaction with parent," in J. of Indian Association for Child and Adolescent Mental Health, 2014, T. 10, No 1, pp. 9-30.

[15] F. Wei and N.N. Pokrovskaia, "Digitizing of regulative mechanisms on the masterchain platform for the individualized competence portfolio", in IEEE VI Forum Strategic Partnership of Universities and Enterprises of Hi-Tech Branches (Science. Education. Innovations) (SPUE) 2017. IEEE Explore, 2017. Pp. 73-76.

[16] Ababkova M.Yu., Pokrovskaia N.N., Trostinskaya I.R. NeuroTechnologies For Knowledge Transfer And Experience Communication // The European Proceedings of Social \& Behavioural Sciences (EpSBS). Vol. XXXV, Pages 1-1452 (19 February 2018). Pp. 10-18.

[17] Mayer J.D., Caruso D.R., Salovey P. Emotional intelligence meets traditional standards for an intelligence // Intelligence. 1999. vol. 27(4). Pp. 267-298. 